R. B. Bates

C. A. Ogle

Carbanion Chemistry 



\section{Carbanion Chemistry}

by

Prof. Dr. Robert B. Bates

and

Prof. Dr. Craig A. Ogle

Arizona (Tucson/USA) 
Die Originalausgabe erscheint im Springer-Verlag

Berlin · Heidelberg $\cdot$ New York · Tokyo

Vertrieb ausschließlich für. die DDR und die sozialistischen Länder

Alle Rechte vorbehalten

(C) Springer-Verlag Berlin $\cdot$ Heidelberg 1983

Erschienen im Akademie-Verlag, DDR-1086 Berlin, Leipziger Straße 3-4

Lizenznummer: $202 \cdot 100 / 547 / 83$

Printed in the German Democratic Republic

Gesamtherstellung: VEB Druckerei „Thomas Müntzer“, 5820 Bad Langensalza

Umschlaggestaltung: Karl Salzbrunn

LSV 1275

Bestellnummer: 7632865 (6793)

04800 